\title{
Strategi Pengembangan Aneka Dodol Berbasis Bahan Baku Lokal di Kabupaten Lampung Barat
}

\author{
Analianasari $^{\mathrm{a}}$, Dayang Berliana ${ }^{\mathrm{b}}$, dan Edy Humaidi ${ }^{\mathrm{c}}$ \\ ${ }^{a}$ Jurusan Ekonomi dan Bisnis, Politeknik Negeri Lampung, Lampung, Indonesia, email: analianasari@polinela.ac.id \\ ${ }^{b}$ Jurusan Ekonomi dan Bisnis, Politeknik Negeri Lampung, Lampung, Indonesia, email: dayang@polinela.ac.id \\ cJurusan Ekonomi dan Bisnis, Politeknik Negeri Lampung, Lampung, Indonesia, email: edyhumaidi145@polinela.ac.id
}

\section{Article Info}

\section{Article history:}

Received 05 Februari 2020

Received in revised form 13 Februari 2020 Accepted 3 Maret 2020

DOI:

https://doi.org/10.32938/ag.v5i2.1000 Keywords:

Dodol

Strategi

Bahan Baku Lokal

Pengembangan

\section{Abstrak}

Tujuan penelitian ini adalah untuk menganalisis strategi pengembangan aneka dodol berbasis bahan baku lokal di Desa Sekincau Kabupaten Lampung Barat. Metode yang digunakan dalam penelitian yaitu analisis SWOT. Responden dipilih secara sengaja (purposive) yaitu di Desa Sekincau dengan jumlah sampel 20 responden dan 4 orang ahli yang berkompeten dalam pengetahuan pengembangan aneka dodol berbasis bahan baku lokal. Hasil penelitian ini menunjukkan bahwa berdasarkan hasil analisis pada matrik SWOT rekomendasi yang harus diberikan adalah strategi "Progresif". Alternatif strategi pengembangan aneka dodol yang dapat diterapkan yaitu (1) Memanfaatkan produk berkualitas (alami) bebas bahan pengawet sebagai potensi pangsa pasar yang masih luas didukung dengan peningkatan minat masyarakat terhadap produk dan menciptakan lapangan pekerjaan baru akibat pasar semakin luas. ( S1, O1.O2.O3) (2) Memanfaatkan unit produksi yang dekat dengan sumber bahan baku dan menciptakan lapangan pekejaan bagi masyarakat sekitar. (S2,O3)

\section{Pendahuluan}

Lampung Barat merupakan Kabupaten yang berada di ujung Propinsi Lampung yang memiliki daerah tujuan wisata yang menarik wisatawan mancanegara maupun nusantara untuk datang berkunjung menikmati berbagai objek wisata. Objek wisata di Lampung Barat sangat lengkap mulai dari laut, danau, pegunungan, Hutan Raya Liwa, maupun wisata petualangan. Hal ini menjadikan potensi kuliner termasuk oleh-oleh khas suatu daerah menjadikan daya tarik tersendiri bagi wisatawan selain beragam destinasi yang menawarkan keindahan alam, hiburan, dan lainnya. Menurut Susilawaty, (2016) industri di tahun 2016, sekitar 98 persen masyarakat membeli oleh-oleh saat berlibur.

Agroindustri pengolahan oleh-oleh khas suatu daerah potensi untuk dikembangkan untuk meningkatkan perekonomian masyarakat. Menurut Asisten Deputi Bidang Pengembangan Destinasi dan Industri Pariwisata, Kementerian Pariwisata Republik Indonesia, Lokot Ahmad Enda, (2016), "bila suatu daerah dapat mengembangkan potensi industri oleh-oleh di setiap daerah Indonesia, maka sektor pariwisata daerah tersebut berkembang dan kontribusi tehadap perekonomian semakin besar terutama bagi wilayah pedesaan. Suryana (2004) menyatakan kegiatan agroindustri merupakan bagian integral dari sektor pertanian, yang mempunyai kontribusi penting dalam proses industrialisasi terutama wilayah pedesaan.

Tanaman hortikultura banyak dibudidayakan di Lampung Barat, khususnya tanaman tomat dan labu siam dan menjadikan kedua komoditas tersebut komoditas unggulan Lampung Barat. Menurut Dinas Pertanian Tanaman Lampung Barat, (2017) komoditas labu siam dan tomat merupakan komoditas utama sayuran dataran tinggi yang memberikan kontribusi dan produktivitas tinggi di Lampung Barat (Tabel 1).

Produktivitas yang tinggi pada komoditas labu siam dan tomat menjadikan ketersediaan dua komoditas tersebut melimpah pada musim panen raya dan harga menjadi murah memunculkan kreasi suatu kelompok wanita tani untuk mengolah labu siam dan tomat menjadi produk olahan aneka dodol yang bernilai bisnis. Kelompok Wanita Tani (KWT) Sekar Wangi merupakan wadah pemberdayaan wanita tani untuk menciptakan lapangan pekerjaan yang produktif dan merupakan usaha yang bersifat padat karya, tidak membutuhkan persyaratan tertentu seperti keterampilan atau keahlian, tingkat pendidikan, menggunakan teknologi yang masih sederhana dan modal yang digunakan relatif terjangkau.

Tabel 1. Data Produksi dan Produktivitas sayuran dataran Tinggi Kabupaten Lampung Barat Tahun 2015 - 2017

\begin{tabular}{|c|c|c|c|c|c|c|}
\hline \multirow{3}{*}{ No Komoditas } & \multicolumn{2}{|c|}{2015} & \multicolumn{2}{|c|}{2016} & \multicolumn{2}{|c|}{2017} \\
\hline & Produksi & Produktivitas & Produksi & Produktivitas & Produksi & Produktivitas \\
\hline & Ton & $\mathrm{kg} / \mathrm{ha}$ & ton & $\mathrm{kg} / \mathrm{ha}$ & ton & $\mathrm{kg} / \mathrm{ha}$ \\
\hline $\begin{array}{ll} & \begin{array}{l}\text { Cabai } \\
\text { besar }\end{array}\end{array}$ & $2.704,3$ & $6.516,4$ & $1.8951,6$ & $6.229,8$ & $3.262,9$ & $8.036,7$ \\
\hline $2 \begin{array}{l}\text { Labu } \\
\text { Siam }\end{array}$ & $11.058,4$ & $61.435,6$ & $17.774,8$ & $93.551,6$ & $17.869,5$ & $93.664,5$ \\
\hline 3 Kubis & $9.038,4$ & $17.862,5$ & $10.301,5$ & $20.002,9$ & $11.620,5$ & $21.374,6$ \\
\hline 4 Tomat & 5.034 .8 & $16.782,7$ & $6.065,6$ & $19.629,8$ & $12.067,4$ & $22.774,8$ \\
\hline 5 Wortel & 4.456 & $13.067,4$ & $6.684,3$ & $18.017,0$ & $5.850,4$ & $17.253,0$ \\
\hline
\end{tabular}

Sumber :([BPS] Badan Pusat Statistik. 2019)

Kegiatan KWT Sekar Wangi merupakan kegiatan ekonomi rakyat berskala kecil dengan jangkauan pemasaran produk yang terbatas. Perkembangan aneka dodol olahan KWT Sekar Wangi tidak terlepas dar berbagai macam masalah dan hambatan seperti kurangnya modal, menajemen yang kurang terorganisasi, dan kurangnya promosi produk sehingga diperlukan strategi untuk pengembangan agroindustri aneka dodol berbasis bahan baku lokal untuk mengatasi masalah dan hambatan tersebut.
Tujuan penelitian ini adalah untuk untuk merumuskan strategi internal dan eksternal dalam mengembangkan agroindustri aneka dodol berbasis bahan baku lokal di Kabupaten Lampung Barat.

\section{Metode}

Penelitian ini dilaksanakan selama 3 bulan, yaitu Maret - Mei 2019 di KWT Sekar Wangi Desa Sekincau Kabupaten Lampung Barat. Data yang diperoleh dianalisis dengan konsep manajemen strategis (Soleh, 2009). Analisis data yang akan dilakukan yaitu analisis deskriptif kualitatif dan kuantitatif Analisis deskriptif kualitatif digunakan untuk mendapatkan gambaran mengenai visi, misi dan mengambarkan lingkungan terkait dengan peluang, ancaman, kekuatan, kelemahan yang dimiliki oleh perusahaan serta perumusan strategi dengan menggunakan matriks SWOT. Sedangkan analisis kuantitatif menggunakan matriks IFE (Internal Factor Evaluation), EFE (Eksternal Factor Evaluation), dan IE (Internal-Eksternal).

Teknik pengumpulan data pada penelitian ini terdiri dari dua yaitu dengan pengumpulan data secara primer dan sekunder. Data primer merupakan data yang diperoleh dan dikumpulkan secara langsung peneliti dari hasil penelitian langsung untuk menjawab masalah atau tujuan penelitian yang dilakukan dengan cara observasi, wawancara, diskusi dan kuesioner. Sedangkan data sekunder merupakan data yang diperoleh dan kumpulkan dari pihak lain (pihak eksternal). Data sekunder diperoleh dari lembaga-lembaga atau instansi terkait seperti Badan Pusat Statistika, monografi Desa Sekincau, Kecamatan Sekincau Lampung Barat. Jenis-jenis data yang digunakan dalam data sekunder ini adalah jumlah produksi aneka dodol, jumlah konsumen, dan data-data lain yang diperlukan untuk menunjang penelitian.

Analisis SWOT. Analisis SWOT digunakan untuk mengetahui Strengths Weakness, Opportunity, dan Threats dalam pengembangan aneka dodol KWT Sari wangi Desa Sekincau Lampung Barat. Selain itu, analisis SWOT biasanya digunakan untuk menganalisis suatu kondisi dimana akan dibuat sebuah rencana untuk melakukan suatu program kerja (Alma, 2008).

\section{Hasil dan Pembahasan}

\subsection{Strategi Pengembangan Aneka Dodol Berbasis Bahan Baku Lokal Di} Kabupaten Lampung Barat

Kekuatan dan kelemahan digolongkan ke dalam faktor internal karena faktor-faktor tersebut merupakan peubah-peubah yang dapat dikendalikan oleh KWT Sekar Wangi. Peluang dan ancaman termasuk dalam faktor eksternal yang terdiri dari peubah-peubah di luar kendali KWT. Berdasarkan informasi yang diperoleh dari hasil wawancara dan pengamatan langsung di lokasi usaha, dapa diidentifikasikan bahwa faktor-faktor strategis internal yaitu kekuatan dan kelemahan pengembangan aneka dodol sedangkan faktor-faktor strategis eksternal yaitu peluang dan ancaman yang dihadapi dalam pengembangan aneka dodol. Faktor-faktor strategis tersebut kemudian di analisis dengan matriks analisis SWOT dan dihasilkan empat strategi yaitu strategi SO, strategi WO, strategi ST, dan strategi WT (Rangkuti, 2005).

Analisis Faktor Internal dan Eksternal Menggunakan Matriks IFAS dan EFAS. Berdasarkan identifikasi terhadap faktor-faktor Internal Factor Analysi Strategic (IFAS) dan Eksternal Factor Analysis Strategic (EFAS) diperoleh kekuatan kelemahan, peluang dan ancaman yang dimiliki aneka dodol KWT Sekar Wangi di Desa Sekincau Lampung Barat.

Tabel 2 menunjukkan bahwa hasil dari faktor strategi internal yang merupakan kekuatan terbesar dan paling berpengaruh terhadap strategi pengembangan aneka dodol berbasis bahan baku lokal di Desa Sekincau Kabupaten Lampung Barat adalah terdapat Produk berkualitas (alami) bebas bahan pengawet yang memiliki skor pembobotan sebesar 0,50. Hal ini menunjukkan bahwa produk yang dihasilkan KWT berasal dari bahan baku yang 
berkualitas dan tidak menggunakan bahan pengawet dan pewarna sintetik. Gula pasir yang ditambahkan pada produk dodol tomat selain berfungsi sebagai pemberi rasa manis juga berfungsi sebagai pengawet.

Matriks Internal Factor Analysis Strategic (IFAS) Tabel 2. Matriks Internal Factor Analysis Strategic (IFAS)

\begin{tabular}{llll}
\hline Faktor-faktor Strategi Internal & Bobot & Rating & $\begin{array}{c}\text { Skor } \\
\text { Pembobotan }\end{array}$ \\
\hline
\end{tabular}

Kekuatan

1. Unit produksi dekat dengan sumber bahan baku

2. Produk berkualitas (alami) bebas

3. Keterlibatan keluarga dalam $0,19 \quad 2,40$ $0,14 \quad 3,56$ 0,46 usaha cukup besar

Teknologi yang digunakan dalam memproduksi relatif sederhana

$0,04 \quad 3,60$

5. Volume penjualan produk dari tahun ke tahun meningkat

\begin{tabular}{lcc}
\hline Sub total & 0,57 & 1,87 \\
\hline
\end{tabular}

Kelemahan

1. Tingkat pendidikan tenaga kerja rendah

2. Kontinuitas pasokan bahan baku yang terbatas pada bulan-bulan tertentu

3. Keterbatasan sarana dan prasarana distribusi produk

4. Belum menggunakan sarana promosi yang beragam

5. Lokasi produksi jauh dari pasar produk

\begin{tabular}{lcc}
\multicolumn{1}{l}{ Sub total } & 0,43 & 1,47 \\
\hline Total & 1,00 & 3,34 \\
\hline Selisih skor & & 0,40
\end{tabular}

Sumber : Data primer diolah, 2019

Penambahan gula pasir sebagai pemberi rasa aneka dodol ditambahkan sesuai dengan konsentrasi tertentu. Analianasari dan Marlinda (2018); Sulardjo dan Agus (2012) menyatakan bahwa peningkatan rasa manis ini disebabkan karena semakin tinggi konsentrasi gula pasir menyebabkan glukosa dan fruktosa yang dihasilkan dari inversi sukrosa juga akan meningkat. Fennema, (1976) gula berfungsi sebagai sumber nutrisi dalam makanan, sebagai pembentuk tekstur dan pembentuk flavor melalui reaksi pencoklatan. Sedangkan Buckle et al.,( 1985) menyatakan bahwa daya larut yang tinggi dari gula dan daya mengikatnya air merupakan sifat-sifat yang menyebabkan gula sering digunakan dalam pengawetan bahan pangan. Bahan baku yang dipergunakan dalam proses produksi aneka dodol berasal dari lingkungan tempat produksi dengan teknik budidaya yang baik. Bahan baku yang digunakan adalah tomat, labu siam, buah naga merah, waluh, dan lain-lain. Bahan baku ini memberikan warna produk sesuai dengan warna bahan bakunya sehingga tidak membutuhkan zat pewarna Bahan baku yang berasal dari tomat akan memberikan warna orange, labu siam memberikan warna hijau, dan buah naga merah memberikan warna ungu. Sedangkan faktor strategi internal yang merupakan kelemahan terhadap strategi pengembangan aneka dodol berbasis bahan baku lokal adalah tingkat pendidikan tenaga kerja rendah dengan skor pembobotan 0,52 . Semua karyawan atau tenaga kerja hanya lulusan SD, SMP, dan SMA namun semua tenaga kerja sudah terlatih dalam proses pengolahan aneka dodol. Pelatihan yang dilakukan tenaga kerja atau karyawannya yaitu melalui diklat kemasan, pemasaran, dan uji produk. Tingkat pendidikan manajemen hanya lulusan pendidikan SMA, namun pengetahuan manajemen usaha diperoleh secara otodidak, dan juga pengalaman dan diklat yang diadakan Dinas Perindustrian, Koperasi dan UMKM PEMDA Kabupaten Lampung Barat dan Pemerintah Provinsi Lampung. Pendidikan tenaga kerja ini meskipun dengan skor yang tertinggi namun tidak berkontribusi secara langsung dalam pengembangan dan penjualan produk.

Berdasarkan perhitungan matriks IFAS untuk kekuatan mendapatkan skor 1,87 dan kelemahan mendapatkan skor 1,47. Sehingga diperoleh total nilai pada posisi internal rata-rata yang dilihat dari bobot yaitu sebesar 3,34. Kondisi ini menunjukan bahwa skor kekuatan pada pengembangan aneka dodol berbasis bahan baku lokal di Desa Sekincau Kabupaten Lampung Barat lebih besar dari pada kelemahannya. Oleh karena itu, harus memanfaatkan kekuatan yang ada untuk mengatasi kelemahan yang ada pada pengembangan aneka dodol KWT Sekar Wangi. Hal ini menunjukkan bahwa pengembangan aneka dodol KWT Sekar Wangi telah mampu merespon faktor internal dengan memanfaatkan kekuatan yang dimiliki sehingga dapat mengatasi kelemahan yang ada.

Berdasarkan Tabel 3 menunjukkan bahwa hasil dari faktor strategi eksternal yang merupakan peluang terbesar dan paling berpengaruh terhadap strategi pengembangan aneka dodol berbasis bahan baku lokal di Desa Sekincau Kabupaten Lampung Barat yaitu Potensi Pangsa pasar yang masih luas dengan nilai skor pembobotan sebesar 0,69 . Hal ini menunjukkan bahwa adanya potensi pangsa pasar terbuka sangat luas. Kabupaten Lampung Barat dikenal memiliki potensi daerah wisata yang tidak kalah indahnya dengan potensi wisata di daerah
Jawa. Jika daerah memiliki tempat wisata maka wisatawan akan tertarik untuk datang berkunjung. Hal ini menjadikan potensi pasar untuk menyediakan oleholeh khas Lampung Barat. Sedangkan faktor strategi eksternal yang merupakan ancaman terbesar dan paling berpengaruh terhadap strategi pengembangan aneka dodol berbasis bahan baku lokal di Desa Sekincau Kabupaten Lampung Barat adalah proses produksi aneka dodol membutuhkan waktu yang lama dengan nilai skor pembobotan sebesar 0,25 . Hal ini menunjukkan bahwa proses produksi olahan aneka dodol membutuhkan waktu yang lama merupakan ancaman terbesar dalam pengembangan aneka dodol dikarenakan saat ini perilaku manusia cenderung serba cepat (instan) artinya untuk regenerasi pelaku usaha dibutuhkan sumber manusia yang tangguh, ulet, dan berjiwa wirausaha.

Matriks Eksternal Factor Analysis Strategic (EFAS)

Tabel 3. Matriks Eksternal Factor Analysis Strategic (EFAS)

\begin{tabular}{|c|c|c|c|c|}
\hline \multicolumn{2}{|c|}{ Faktor-faktor Strategi Eksternal } & Bobot & Rating & $\begin{array}{c}\text { Skor } \\
\text { Pembobotan }\end{array}$ \\
\hline \multicolumn{5}{|c|}{ Peluang } \\
\hline 1. & Potensi Pangsa pasar yang masih luas & \multirow{2}{*}{0,19} & \multirow{2}{*}{3,64} & \multirow{2}{*}{0,69} \\
\hline 2. & Minat masyarakat terhadap produk & & & \\
\hline \multirow{2}{*}{3.} & olahan meningkat & 0,15 & 3,84 & 0,58 \\
\hline & \multirow{2}{*}{$\begin{array}{l}\text { Adanya pendapatan dari usaha aneka } \\
\text { dodol }\end{array}$} & 0,06 & 3,96 & 0,24 \\
\hline \multirow{2}{*}{$\begin{array}{l}4 . \\
5 .\end{array}$} & & 0,10 & 3,48 & 0,35 \\
\hline & Iklim usaha yang terbuka & 0,05 & 3,92 & 0,20 \\
\hline \multicolumn{2}{|c|}{ Sub total } & 0,55 & & 2,05 \\
\hline
\end{tabular}

Ancaman

1. Proses produksi dengan waktu yang lama

2. Sarana dan prasarana produksi yang

kurang memadai

$0,17 \quad 1,48$

$0,07 \quad 1,88$

$0,05 \quad 2,44$

$0,06 \quad 3,16$

$0,10 \quad 2,48$

0,13

0,12

bahan baku

4. Kemasan produk yang sederhana

5. Ketersediaan bahan baku yang berfluktuasi

\begin{tabular}{lll}
\hline Sub total & 0,45 & 0,94 \\
\hline Total & 1,00 & 2,99 \\
\hline Selisih skor & & 1,11 \\
\hline
\end{tabular}

Sumber : Data primer diolah, 2019

Berdasarkan perhitungan matriks EFAS untuk peluang mendapatkan skor 2,05 dan ancaman mendapatkan skor 0,94 . Sehingga di peroleh total nilai eksternal rata-rata yaitu sebesar 2,99. Hal ini menunjukkan bahwa skor peluang yang dimiliki KWT Sekar Wangi lebih besar dari ancamannya, sehingga dapat memanfaatkan peluang untuk mengantisipasi kemungkinan ancaman yang dihadapi. Hal ini menunjukkan bahwa pengembangan aneka dodol dengan memanfaatkan bahan baku lokal telah mampu merespon faktor eksternal dengan memanfaatkan peluang yang ada sehingga dapat mengatasi ancaman eksternal.

$\begin{array}{cc}\text { skor kekuatan - skor kelemahan } & : \text { skor peluang - skor ancaman } \\ 2 & 2 \\ 1,87-1,47 & : 2,05-0,94 \\ 2 & 2 \\ 0,40 & : 1,11\end{array}$

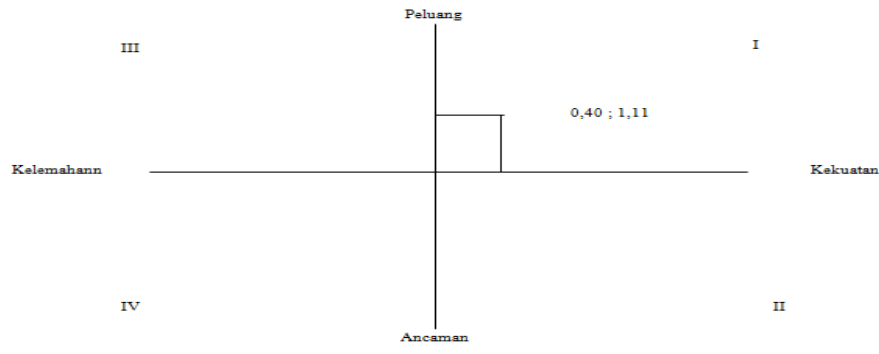

Gambar 1. Grafik Analisis SWOT Pengembangan Aneka Dodol

Analisis SWOT digunakan untuk mengidentifikasi berbagai faktor untuk merumuskan strategi. Berdasarkan data faktor internal dan faktor eksternal didapatkan skor pembobotan sebagai berikut : faktor kekuatan $=1,87$, faktor kelemahan $=1,47$, faktor peluang $=2,05$, dan faktor ancaman $=0,94$. Analisis SWOT yang dilakukan sebelumnya dapat digunakan sebagai dasar dalam penentuan strategi pengembangan aneka dodol berbasis bahan baku lokal di desa Sekincau Kabupaten Lampung barat kedepan. Analisis SWOT dibangun berdasarkan hasil analisis faktor-faktor strategis internal maupun eksternal yang terdiri dari berbagai faktor kekuatan, kelemahan, peluang dan ancaman. Hasil analisis pada gambar 1 grafik analisis SWOT di peroleh titik koordinat $(0,40$; 1,11) yang mana koordinat ini masuk pada kuadran I, yakni posisi ini menandakan sebuah usaha atau organisasi yang kuat dan berpeluang (Pearce dan Robinson, 1998). Rekomendasi strategi yang diberikan adalah “ Progresif” artinya usaha dalam kondisi prima dan mantap sehingga sangat mungkin untuk 
terus melakukan ekspansi, meningkatkan pertumbuhan dan meraih kemajuan secara maksimal.

Perioritas strategi pengembangan dengan Analisis SWOT dengan hasil penggabungan perhitungan pembobotan rating IFAS dan EFAS dapat dilihat pada Tabel 4.

Tabel 4. Pembobotan Rating IFAS dan EFAS

\begin{tabular}{ccc}
\hline & $\mathbf{O}=\mathbf{2 , 0 5}$ & $\mathbf{T}=\mathbf{0 , 9 4}$ \\
\hline $\mathbf{S}=\mathbf{1 , 8 7}$ & SO $=3,89$ & $\mathrm{ST}=2,81$ \\
$\mathbf{W}=\mathbf{1 , 4 7}$ & WO $=3,52$ & WT $=2,41$ \\
\hline
\end{tabular}

Berdasarkan Tabel 4 menunjukkan bahwa hasil pembobotan rating hasi SWOT, maka dapat disusun prioritas strategi berdasarkan kombinasi strategi yang paling tinggi sampai dengan paling rendah, dapat dilihat pada Tabel 5.

Tabel 5. Tingkat Prioritas Strategi SWOT

\begin{tabular}{clc}
\hline Prioritas & \multicolumn{1}{c}{ Strategi } & Bobot Nilai \\
\hline I & Strengh-Opportunity $(S O)$ & 3,89 \\
II & Strengh-Threat $(S T)$ & 2,81 \\
III & Weakness-Opportunity $(W O)$ & 3,52 \\
IV & Weakness-Threat $(W T)$ & 2,41 \\
\hline
\end{tabular}

Berdasarkan Tabel 5 menunjukkan bahwa hasil interaksi IFAS dan EFAS yang menghasikan alternatif strategi yang mendapatkan bobot tertinggi adalah Strengh-Opportunity (SO) dengan skor 3,89 diterjemahkan sebagai strategi yang menggunakan kekuatan untuk memanfaatkan peluang. Strategi untuk pengembangan aneka dodol memiliki bobot kekuatan yang lebih besar dari pada kelemahan, sedangkan bobot peluang lebih besar daripada ancaman dalam pengembangan aneka dodol berbasis bahan baku lokal di Desa Sekincau

Tujuan dari tahap analisis terhadap faktor-faktor strategi dengan matrik SWOT adalah untuk menghasilkan altenatif strategi yang layak. Berdasarkan matrik SWOT dihasilkan strategi Strengh-Opportunity (SO), Strengh-Threat (ST), Weakness-Opportunity (WO), dan Weakness-Threat (WT). Hasil analisis terhadap empat strategi yang disarankan dapat dilihat pada Tabel 6 .

Berdasarkan hasil pembobotan nilai tertinggi adalah strategi StrenghOpportunity (SO) terletak pada kuadran I. Pada kuadran ini merupakan situasi yang sangat kuat dan berpeluang. Tingginya strategi nilai prioritas SO bukan berati strategi lain yang memiliki nilai rendah tidak bermanfaat dan tidak perlu diterapkan. Akan tetapi, apabila ingin mendapatkan hasil yang maksimal perlu ditunjang dengan strategi ST, WO dan WT. Menurut Sanjaya (2017) Maka strategi yang tepat adalah dengan menggunakan kekuatan untuk memanfaatkan peluang jangka panjang yang lebih besar, yaitu pertumbuhan dengan integrasi horizontal. Dimana integrasi horizontal tersebut dapat mendukung strategi agresif yaitu sistem jemput bola dengan membuat cabang-cabang atau serta outlet-outlet pembayaran transaksi Aqiqah diberbagai daerah (kecamatan). Alternatif strategi yang dapat diterapkan pada usaha KWT Sekar Wangi yaitu dengan memanfaatkan produk berkualitas (alami) bebas bahan pengawet sebagai potensi pangsa pasar yang masih luas didukung dengan peningkatan minat masyarakat terhadap produk dan menciptakan lapangan pekerjaan baru akibat pasar semakin luas, selain itu perlu memanfaatkan unit produksi yang dekat dengan sumber bahan baku dan menciptakan lapangan pekejaan bagi masyarakat sekitar. Peningkatan kualitas tenaga kerja wajib dilakukan, hal ini dapat dilakukan dengan beberapa cara yaitu training psikologi, training motivasi, pelatihan kerja berbagai kejuruan, penerapan disiplin kerja, dan manajemen control (Adianto and Fedryansyah 2018; Humaidi, et al 2017).

\section{Simpulan}

Strategi yang dapat dilakukan dalam pengembangan aneka dodol berbasis bahan baku lokal di Desa Sekincau Kabupaten Lampung Barat berada pada koordinat $(0,40 ; 1,11)$ yaitu terletak pada kuadran I posisi ini menandakan sebuah usaha yang kuat dan memiliki berpeluang untuk dikembangkan. Alternatif strategi pengembangan aneka dodol yang dapat diterapkan yaitu (1) Memanfaatkan produk berkualitas (alami) bebas bahan pengawet sebagai potensi pangsa pasar yang masih luas didukung dengan peningkatan minat masyarakat terhadap produk dan menciptakan lapangan pekerjaan baru akibat pasar semakin luas. ( S2, O1.O2.O3) (2) Memanfaatkan unit produksi yang dekat dengan sumber bahan baku dan menciptakan lapangan pekejaan bagi masyarakat sekitar. $(\mathrm{S} 1, \mathrm{O} 3)$
Tabel 6. Matriks SWOT Pengembangan Aneka Dodol Berbasis Bahan Baku Lokal di Desa Sekincau Kabupaten Lampung Barat

\begin{tabular}{|c|c|c|}
\hline $\begin{array}{c}\begin{array}{c}\text { Internal } \\
\text { Factor } \\
\text { Analysis } \\
\text { Strategic } \\
\text { (IFAS) }\end{array} \\
\text { Eksternal } \\
\text { Analysis } \\
\text { Stretegic (EFAS) }\end{array}$ & \begin{tabular}{|l} 
Kekuatan (S) \\
1. Produk \\
berkualitas \\
(alami) bebas \\
bahan pengawet \\
2. Unit produksi \\
dekat dengan \\
sumber bahan \\
baku \\
3. Teknologi yang \\
digunakan \\
dalam \\
memproduksi \\
relatif \\
sederhana
\end{tabular} & $\begin{array}{l}\text { Kelemahan (W) } \\
\text { 1. Tingkat pendidikan } \\
\text { TK rendah } \\
\text { 2. Kontiunitas pasokan } \\
\text { bahan baku yang } \\
\text { terbatas pada bulan } \\
\text { tertentu } \\
\text { 3. Keterbatasan sarana } \\
\text { dan prasarana } \\
\text { distribusi produk }\end{array}$ \\
\hline $\begin{array}{l}\text { Peluang }(\mathrm{O}) \\
\text { 1.Potensi pangsa } \\
\text { pasar yang masih } \\
\text { luas } \\
\text { 2. Minat masyarakat } \\
\text { terhadap produk } \\
\text { olahan meningkat } \\
\text { 3. Penciptaan } \\
\text { lapangan pekerjaan }\end{array}$ & $\begin{array}{l}\text { Strategi } \mathrm{S}-\mathrm{O} \\
\text { 1. Memanfaatkan } \\
\text { produk } \\
\text { berkualitas } \\
\text { (alami) bebas } \\
\text { bahan pengawet } \\
\text { sebagai potensi } \\
\text { pangsa pasar } \\
\text { yang masih luas } \\
\text { didukung } \\
\text { dengan } \\
\text { peningkatan } \\
\text { minat } \\
\text { masyarakat } \\
\text { terhadap } \\
\text { produk dan } \\
\text { menciptakan } \\
\text { lapangan } \\
\text { pekerjaan baru } \\
\text { akibat pasar } \\
\text { semakin luas. ( } \\
\text { S1, O1.O2.O3) } \\
\text { 2. Memanfaatkan } \\
\text { unit produksi } \\
\text { yang dekat } \\
\text { dengan sumber } \\
\text { bahan baku dan } \\
\text { menciptakan } \\
\text { lapangan } \\
\text { pekejaan bagi } \\
\text { masyarakat } \\
\text { sekitar. } \\
\text { (S2,O3) }\end{array}$ & $\begin{array}{l}\text { Strategi } \mathrm{W}-\mathrm{O} \\
\text { 1. Meningkatkan } \\
\text { pendidikan } \\
\text { pengetahuan dan } \\
\text { keterampilan tenaga } \\
\text { kerja sehingga dapat } \\
\text { meningkatkan potensi } \\
\text { pangsa pasar produk } \\
\text { karena } \quad \text { minat } \\
\text { masyarakat semakin } \\
\text { luas. (W1,O1,O2) } \\
\text { 2. Memperluas } \\
\text { hubungan pedagang } \\
\text { pengumpul atau petani } \\
\text { besar untuk } \\
\text { ketersediaan bahan } \\
\text { baku sehingga dapat } \\
\text { meningkatkan potensi } \\
\text { pasar produk dan } \\
\text { lapangan pekerjaan } \\
\text { dapat tetap } \\
\text { berlangsung (W2,O2) }\end{array}$ \\
\hline \begin{tabular}{|l} 
Ancaman $(\mathrm{T})$ \\
1.Proses produksi \\
yang lama \\
2. Ketersediaan bahan \\
baku berfluktuatif \\
3. Kemasan produk \\
yang masih \\
sederhana
\end{tabular} & $\begin{array}{l}\text { Strategi S-T } \\
\text { 1. Memanfaatkan } \\
\text { keunggulan } \\
\text { produk sebagai } \\
\text { produk yang } \\
\text { bebas bahan } \\
\text { pengawet } \\
\text { sehingga KWT } \\
\text { tetap melakukan } \\
\text { produksi } \\
\text { walaupun } \\
\text { membutuhkan } \\
\text { waktu produksi } \\
\text { yang lama dan } \\
\text { kemasan produk } \\
\text { masih sederhana } \\
\text { (S1,T1,T3) } \\
\text { 2. Mengoptimalkan } \\
\text { unit produksi } \\
\text { yang dekat } \\
\text { dengan sumber } \\
\text { bahan baku untuk } \\
\text { mengatasi } \\
\text { ketersediaan } \\
\text { bahan baku yang } \\
\text { berfluktuatif. } \\
\text { (S2,T2) }\end{array}$ & \begin{tabular}{|l} 
Strategi $\mathrm{W}-\mathrm{T}$ \\
1. Meningkatkan \\
pendidikan TK \\
sehingga mampu \\
membuat kemasan \\
produk yang \\
inovatif. (W1,T3)) \\
2. Meningkatkan \\
ketersediaan stok \\
BB untuk mengatasi \\
ketersediaan BB \\
yang berfluktuatif \\
(W2,T2)
\end{tabular} \\
\hline
\end{tabular}


Pustaka

[BPS] Badan Pusat Statistik. 2019. Lampung Dalam Angka 2019. Bandar Lampung: Badan Pusat Statistik Provinsi Lampung.

Adianto, Jepi, and Muhammad Fedryansyah. 2018. "Peningkatan Kualitas Tenaga Kerja Dalam Menghadapi Asean Economy Community.” Jurnal Pekerjaan Sosial 1(2): 77-86.

Alma, B. 2008. Manajemen Pemasaran Dan Pemasaran Jasa. Bandung: CV. Alfabeta.

Analianasar, Ai; Marlinda Apriyani. 2018. "Sifat Organoleptik dan Nilai Tambah Yogurt Beku dengan Penambahan Ekstrak Kulit Buah Naga Merah (Hyloceneus polyrhizus)." Jurnal Teknologi \& Industri Hasil Pertanian 24(1): 59-66.

Buckle, K.A., R.A. Edward, G.h. Fleet Dan, and M. Wooton. 1985. Ilmu Pangan. eds. Purnomo Purnomo and Aiono Adiono. Jakarta.: Universitas Indonesia,.

Dinas Pertanian Tanaman Lampung Barat. 2017. "Data Produksi Sayuran."

Humaidi Edy, Putri Suci Asriani, Basuki Sigit Priyono. 2017. "Strategi Keberlanjutan Agribisnis Beras Organik Di Kelompok Tani Handayani Kecamatan Bts Ulu Kabupaten Musi Rawas." Unib Schoolar Repository. http://repository.unib.ac.id/id/eprint/15023.

Fennema, O R. 1976. Principle of Food Science. Part 1. Food Chemistry. New York.: Marcel Dekker Inc.

Pearce, J.A.II., dan Robinson, R.B.Jr., (1998). Manajemen Strategis. Jakarta : Binarupa Aksara

Rangkuti, F. 2005. Analisis SWOT Teknik Membedah Kasus Bisnis. Jakarta: Gramedia Pustaka Utama.

Sanjaya, Rendi Septi. 2017. "Strategi Pemasaran Dalam Meningkatkan Omzet Penjualan Unit Usaha Aqiqah Pada Laz Nurul Hayat Medan (Pendekatan Analisis SWOT)."

Soleh, J. 2009. "Strategi Pengembangan Usaha Ternak Sapi Perah Di Kecamatan Sukaresmi Kabupaten Cianjur Jawa Barat.” Institut Pertanian Bogor.

Sulardjo, dan Santoso Agus. 2012. "Pengaruh Konsentrasi Gula Pasir Terhadap Kualitas Jelli Buah Rambutan.” Magistra XXIV(82): 79-87.

Suryana, A. 2004. "Arah, Strategi Dan Program Pembangunan Pertanian 20052009."

Susilawaty, Desy. 2016. "Kontribusi Oleh-Oleh Dalam Dunia Pariwisata." Koran Republika (September): 2016. 